\title{
The paradox of aging and health-related quality of life in Asian Chinese: results from the Healthy Aging Longitudinal Study in Taiwan
}

\author{
Han-Yun Tseng ${ }^{1,2}$, Corinna Löckenhoff ${ }^{2}$, Chun-Yi Lee', Shu-Han Yu ${ }^{3}$, I-Chien Wu' ${ }^{1}$,Hsing-Yi Chang ${ }^{1}$,
} Yen-Feng Chiu ${ }^{1 * \dagger}$ (D) and Chao Agnes Hsiung ${ }^{1+}$

\begin{abstract}
Background: Declines in health, physical, cognitive, and mental function with age suggest a lower level of healthrelated quality of life (HRQoL) in late life; however, previous studies found that the associations were weak and varied, depending on the study designs and cohort characteristics.

Methods: The present study examined the paradox of aging in an East Asian context by regressing the age patterns of objective health indicators (physical, cognitive, and mental function), and subjective HRQoL (12-item Short Form, SF-12), on the independent and interactive effects of age and physical function in a cohort study of 5022 community-dwelling adults aged 55 and older in Taiwan.

Results: Age patterns differed across measures. The SF-12 mental health score (MCS) showed a slight positive association with age and this effect remained stable after controlling for various age-related covariates. The SF-12 physical health score (PCS), in turn, was negatively associated with age. Age differences in PCS were fully explained by age decrements in objective physical health. However, consistent with the so-called paradox of aging, the association between objective and subjective physical health weakened with age.

Conclusion: These findings add to prior evidence indicating that — in spite of objective health decrements subjective HRQoL is maintained in later life among Asian Chinese. Also, these paradoxical patterns appear to vary for mental and physical components of HRQoL, and future research is needed to explore the underlying mechanism.
\end{abstract}

Trial registration: Healthy Aging Longitudinal Study in Taiwan (HALST) is retrospectively registered at ClinicalTrials. gov on January 24, 2016 with trial registration number NCT02677831.

Keywords: Mental health score, Physical health score, Objective physical health, subjective physical health

\section{Background}

Self-reported quality of life usually follows a U-shaped or curvilinear relationship over the course of the life cycle $[13,17]$ with the lowest points reported between the person's mid-30s and early 50s in the United States, Canada, Britain, most West European countries,

\footnotetext{
* Correspondence: yfchiu@nhri.edu.tw

${ }^{\dagger}$ Yen-Feng Chiu and Chao Agnes Hsiung contributed equally to this work. ${ }^{1}$ Institute of Population Health Sciences, National Health Research Institutes, 35 Keyan Rd., Zhunan, Miaoli County 35053, Taiwan

Full list of author information is available at the end of the article
}

Australia, and New Zealand [4, 10, 11, 43]. The results have been found to be fairly robust for men and women $[4,22]$, and are seen in both raw and covariate-adjusted data [17]. One possible explanation for the lower quality of life in midlife is that deteriorating health, accumulated life stressors, and competing demands from work and family can be difficult and detrimental to well-being [7, 40].

However, what interested gerontological researchers, and was initially considered a mystery, was the robust upturn of subjective well-being found later in life even 
though health-related resources (e.g., health and function) are progressively lost. Researchers using longitudinal data of 22 waves from the Veteran's Affairs Normative Aging Study found the highest well-being scores were reached in late life [34]. Similarly, in a crosssectional analysis, when potential covariates (e.g., sex, education, income, driving ability, activities of daily living (ADL), social relationship, living status, and depression) were adjusted, researchers in the English Longitudinal Study of Ageing (ELSA) observed that the quality of life increased from age 50, peaked at age 68, and, by age 86 , gradually declined to the same level as at the age of 50 [35]. Such consistent reports of stable or increased levels of subjective well-being among older adults also suggest that the correspondence between objective health and subjective well-being weakens with age [24]. That subjective well-being is maintained or even improved later in life despite so many welldocumented losses that occur with aging has been labeled the "paradox of aging" [33].

Subsequent research has begun to unravel the increasing decoupling of subjective and objective health with age - the core of the paradox of aging. Life-course perspectives [3] explain this phenomenon by arguing that although losses in objective health and socioeconomic status are apparent with aging, the effects of considerable reserves and continued gains in psychosocial functioning on quality of life are also noticeable [41]. The latter were found to compensate for losses in health even until the very last phase of life [27]. Prior studies have also documented a relevant range of covariates that serve as challenges and resources in later life. For example, more favorable chair stand scores and walk times were associated with higher HRQoL [18]. Psychosocial factors, such as depression, have been consistently found to have a substantial influence on quality of life in older adults beyond physical function and health status [26]. Similarly, social relationships not only promote subjective well-being when one gets older $[2,5]$ but also explain over $20 \%$ of the variance in life satisfaction in old age [14]. Meanwhile, it is important to acknowledge that age-related shifts in risk and resilience factors may not function consistently across different demographic and social groups. Individual as well as cultural variance in predictors of subjective well-being requires further consideration [36].

Compared to the wealth of literature on age trajectories and the aging paradox of subjective well-being in the West, fewer studies in Asian populations are available, and it is not clear to what extent such patterns are universal [42]. Chen [9], using the Survey of Health and Living Status of the Elderly in Taiwan in 1989 and 1993, revealed that, after controlling for age-related correlates, higher subjective well-being was found among older versus middle-aged birth cohorts. Likewise, researchers in China found the familiar U-shaped relationship between age and subjective well-being in a Chinese sample aged 15-102 years [44]. To our knowledge, none of these studies in East Asian populations have explicitly tapped into the issue of the paradox of aging. It is also unknown if the cross-sectional age differences found in Chen's study 20 years ago would apply to adults currently aging in Taiwan, where significant social, economic, and demographic changes have been observed in the new millennium [30].

\section{The present study}

The present study explored the paradox of aging in health-related quality of life among a large, recent, and nationally representative Taiwanese sample by investigating cross-sectional age patterns in HRQoL and examining age differences in the association between objective physical functioning and HRQoL.

Several methodological improvements are worth mentioning. First, rather than relying on single-item assessments of HRQoL, we used the well-established SF-12 scale, which has been shown to be valid across cultures [28] and captures the multidimensional nature of HRQoL by assessing both physical domains (physical component score, PCS) and mental domains (mental component score, MCS) of quality of life [19, 31]. Moreover, rather than relying on self-reported measures of health status, which may be subject to social comparison and appraisal processes, we utilized objective, performance-based measures of physical function, along with well-established, standardized questionnaires for other health covariates. Finally, we systematically compared the age patterns of HRQoL (PCS and MCS, respectively) before and after controlling for a range of relevant demographic, socioeconomic status (SES), and health covariates in order to gain a full picture of actual and pure age effect [22].

We depicted the cross-sectional age patterns of objective health indicators (physical, cognitive, and mental function) and HRQoL (PCS and MCS, respectively). According to the paradox of aging, we expected to see divergent age patterns, including decrements in PCS but stable, if not improved, MCS. It is of particular interest in the current study to see if age would remain a significant predictor for HRQoL when age-related changes were considered. Further, we examined the association between an objective health indicator (physical function) and subjective HRQoL and how it varied as a result of age. We hypothesized that, with advancing age, the predictive value of physical function for HRQoL would be minimized. In other words, the effects of objective health on subjective HRQoL (PCS and MCS) are moderated by age. 


\section{Methods}

\section{Data and sample}

The data was obtained from the baseline sample of the Healthy Aging Longitudinal Study (HALST; for details, see Hsu et al.) [23]. The baseline sample was collected in 2009-2013 from community-dwelling older adults aged 55 and above across Taiwan $(n=5664$; age range $=55.1-$ 104.2 years, mean $=69.6$ years, $\mathrm{SD}=8.3 ; 52.8 \%$ female) . The sampling distributions of gender and education attainments in the HALST study represented the sociodemographic distributions of Taiwanese population in urban and rural areas. Individuals who had any of the following four conditions were excluded from the study: (1) bedridden, (2) deaf or difficulty hearing, (3) demented, and (4) too frail. Figure 1 presents a flowchart of the data collection process for the HALST and sample selection for the current study.

\section{Measures}

\section{Outcome variables}

Health-related quality of life Health-related quality of life was assessed with the SF-12v2 [46]. Compared to the longer version (i.e., 36-item Short Form (SF-36)), the SF$12 \mathrm{v} 2$ is better suited for older adults because it is less time consuming and excludes questions about work [32]. Previous studies have demonstrated the sound psychometric properties [45] and cross-cultural compatibility of the SF-12 [28], and it is considered suitable for application to Asian populations. The traditional Chinese version of the SF-12v2 was obtained through licensing from QualityMetric (http://www.qualitymetric.com/). The SF-12v2 includes two questions concerning physical function, two questions on role limitations due to physical health problems, one question on bodily pain, one question on general health perceptions, one question on vitality, one questions on role limitation due to emotional problems, and two questions on psychological distress and well-being. Scoring followed the standard SF12 algorithms in the user's manual for the SF-12v2 [46], yielding two aggregated summary measures: the physical component summary score (PCS) and mental component summary score (MCS).

\section{Predictive and controlled variables}

Several age-related covariates for HRQoL were selected for the present study based on the results of prior research in China, Hong Kong, and Taiwan [28, 29, 44], including health status, physical function, social support, and a range of socio-demographic variables.

Physical function Performance-based mobility was measured by the Short Physical Performance Battery (SPPB) [20, 21]. The SPPB contains three components: standing balance, a timed 4-m walk, and chair stands. The standing balance activity required participants to maintain side-by-side, semi-tandem, and tandem stances for $10 \mathrm{~s}$. The 4-m walk took place twice, and the faster time of the two attempts was used. The chair stands activity asked participants to rise from a chair five times with arms across their chest. Times for completing the 4-m walk and chair stands were categorized into quintiles, ranging from 0 to 4 . Individuals unable to complete the task received a score of 0 . The sum of the three components comprised the final SPPB summary score, with a possible range from 0 to 12 - the higher the score, the better the physical function.

Cognitive function The Mini-Mental State Examination (MMSE) [16] was used to screen and assess cognitive function, including memory, attention, and language. The standard MMSE form is currently used worldwide with minor modifications to adapt to differences in language and cultural conceptualization of the questions. The MMSE has been used extensively in clinical population-based research to measure cognitive function, estimate the severity and progression of cognitive impairment, track the course of cognitive change over time, and screen for dementia [12]. MMSE scores range from 0 to 30, with higher scores indicating better cognitive function.

Mental function The self-reported Center for Epidemiologic Studies Depression Scale (CES-D) [37] was used to measure depressive symptoms severity in the general population. The CES-D contains 20 items regarding symptoms that occurred in a week prior to the interview. Each response could range from 0 to 3 , indicating the frequency of the described symptoms. The final score ranges from 0 (best possible) to 60 (worst), and the cutoff point recommended for depression is 16 .

Socio-demographic variables A range of sociodemographic factors, which have been shown to be associated with HRQoL, were selected based on the literature. These included levels of education $(0=$ illiterate, 1 = elementary school, 2 = middle school or higher), residence $(0=$ rural, $1=$ urban $)$, employment $(0=$ unemployed, 1 =employed), living arrangement $(0=$ living alone, 1 = cohabitant $)$ partnership status $(0=$ single, widowed, divorced, or separated, $1=$ married or partnered), and gender $(0=$ male, $1=$ female $)$.

\section{Analytic strategy}

The first analysis was descriptive, and categorized participants by demographics, socioeconomic, objective health indicators, and HRQoL. The Kruskal-Wallis or chisquare test was used to examine the difference in 


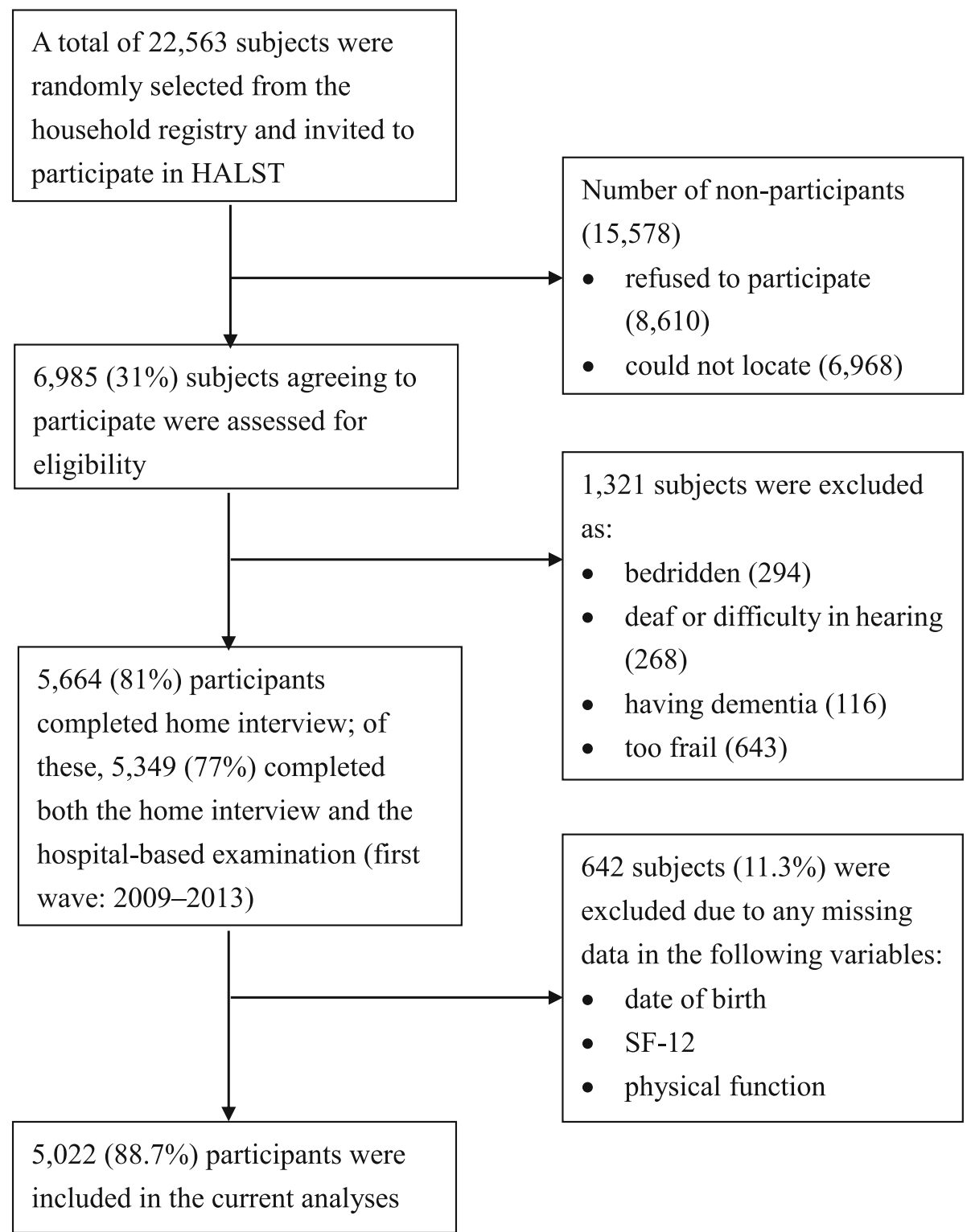

Fig. 1 A flowchart of the data-collection process and attrition for the HALST study (baseline: 2009-2013), and the data selection for the current study ( $n=5022)$

continuous or categorical variables of interest between the young old and the older old ( $\geq 65$ years old). The second analysis used multiple linear regression models predicting PCS and MCS. Models included: (1) age (tested by linear, quadratic, and cubic fashion for best fit); (2) as previous, plus demographic, SES, and covariates, including gender, education level, partnership, residency, living arrangement, MMSE, and CES-D; (3) as previous, plus objective health indicators, including handgrip strength and SPPB; (4) as previous, plus interaction terms of age and objective health indicators. All analyses described in the following section were performed using SAS version 9.4 statistical software (SAS Institute Inc., Cary, NC,
USA). LOESS (LOcally regrESSion) smoothing method was used to model the association between age and PCS or MCS. The fitted curves were plotted using R computing package.

\section{Results}

Table 1 presents descriptive statistics for the variables under consideration in the present study. The mean scores for PCS and MCS in our sample are $46.8 \pm 0.1$ and $59.3 \pm 0.1$, respectively. The average age is $69.6 \pm 0.1$ years (ranging from 55.1 to 104.2 years), and $52.8 \%$ are female. The vast majority of participants (85.9\%) had at least an elementary school education level when leaving 
Table 1 Descriptive statistics. Mean (SE) or proportions (\%)

\begin{tabular}{|c|c|c|c|}
\hline Characteristics & All & Young old $(<65$ y) & Old old $(\geq 65 y)$ \\
\hline N (\%) & $5664(100.0)$ & $1686(29.8)$ & $3978(70.2)$ \\
\hline Age $(\text { mean } \pm S E)^{* *}$ & $69.6 \pm 0.1$ & $59.8 \pm 0.06$ & $73.8 \pm 0.09$ \\
\hline \multicolumn{4}{|l|}{ Sociodemographic characteristics } \\
\hline Female (\%) & $2988(52.8)$ & $886(52.6)$ & $2102(52.8)$ \\
\hline \multicolumn{4}{|l|}{ Education level** } \\
\hline Illiterate & $799(14.1)$ & $49(2.9)$ & $750(18.9)$ \\
\hline Elementary school & $2322(41.0)$ & $570(33.8)$ & $1752(44.1)$ \\
\hline Middle school or higher & $2539(44.9)$ & $1065(63.2)$ & $1474(37.1)$ \\
\hline Employed (\%)** & $1433(25.3)$ & $783(46.4)$ & $650(16.3)$ \\
\hline Partnered $(\%)^{* *}$ & $4159(73.4)$ & $1438(85.3)$ & $2721(68.4)$ \\
\hline Reside in urban area (\%) & $2911(51.4)$ & $891(52.8)$ & $2020(50.8)$ \\
\hline Cohabitant $(\%)^{* *}$ & $5155(91.0)$ & $1579(93.7)$ & $3576(89.9)$ \\
\hline \multicolumn{4}{|l|}{ Health-related variables } \\
\hline Handgrip strength $(\text { mean } \pm S E)^{* *}$ & $29.0 \pm 0.1$ & $33.1 \pm 0.2$ & $27.3 \pm 0.2$ \\
\hline SPPB $(\text { mean } \pm S E)^{* *}$ & $10.4 \pm 0.03$ & $11.4 \pm 0.03$ & $10.0 \pm 0.05$ \\
\hline MMSE $(\text { mean } \pm S E)^{* *}$ & $26.2 \pm 0.05$ & $28.0 \pm 0.06$ & $25.4 \pm 0.06$ \\
\hline Depression (CES-D > 16; \%) & $318(5.6)$ & $98(5.8)$ & $220(5.5)$ \\
\hline \multicolumn{4}{|l|}{ HRQoL } \\
\hline $\mathrm{PCS}(\text { mean } \pm \mathrm{SE})^{* *}$ & $46.8 \pm 0.1$ & $49.3 \pm 0.2$ & $45.7 \pm 0.2$ \\
\hline MCS $(\text { mean } \pm \text { SE) })^{* *}$ & $59.3 \pm 0.1$ & $58.7 \pm 0.2$ & $59.6 \pm 0.1$ \\
\hline
\end{tabular}

Kruskal-Wallis test or $x_{2}^{2}$ test was conducted to detect the differences between two groups (Young old, and Old old)

${ }^{*} p$-value $<0.05,{ }^{* *} p$-value $<0.001$

a Urban: *City: Taipei, Changhua, Kaohsiung, Hualien *Rural: Miaoli, Yangmei, Shoufeng, Chiayi

school. The mean MMSE score is $26.2 \pm 0.05$, which falls within the normal cognitive function. A total of $5.6 \%$ reported depressive symptoms in the past 2 weeks (CES$\mathrm{D}>16)$. The mean handgrip strength is $29.0 \pm 0.1(\mathrm{~kg})$, which falls within the range of normal to strong upper limb strength. The average SPPB score is $10.4 \pm 0.03$ out of 12 .

We analyzed the zero-order correlations among variables of interest in our model first. As seen in Table 2, age was negatively associated with handgrip strength $(r=-.33, p<.001)$, SPPB $(r=-.42, p<.001)$, and PCS $(r=-.26, p<.001)$, but slightly positively associated with MCS $(r=.063, p<.001)$. Thus, older age was accompanied by more constraints in physical and cognitive function, and lower HRQoL in the physical domain (PCS), whereas HRQoL in the psychosocial domain (MCS) was preserved, if not slightly improved, with age. The divergent cross-sectional age trajectories of PCS and MCS before controlling for covariates are visualized in Fig. 2.

Two further findings in Table 2 deserve mention. First, the zero-order correlation between PCS and MCS is small and negative $(\mathrm{r}=-.048, p<.001)$, corresponding to the literature suggesting independence of subjective well-being in different domains [15]. Second, while both PCS and MCS were significantly correlated with all

Table 2 Intercorrelations among age, health-related variables, and HRQoL $(n=5022)$

\begin{tabular}{|c|c|c|c|c|c|c|c|}
\hline Variables & Age & MMSE & CES-D & Handgrip strength & SPPB & PCS & MCS \\
\hline Age & - & $-0.40^{* *}$ & $0.046^{*}$ & $-0.33^{* *}$ & $-0.42^{* *}$ & $-0.26^{* *}$ & $0.063^{* *}$ \\
\hline MMSE & $-0.40^{* *}$ & - & $-0.18^{* *}$ & $0.39^{* *}$ & $0.43^{* *}$ & $0.26^{* *}$ & $0.049^{* *}$ \\
\hline CES-D & $0.046^{*}$ & $-0.18^{* *}$ & - & $-0.18^{* *}$ & $-0.24^{* *}$ & $-0.25^{* *}$ & $-0.67^{* *}$ \\
\hline Handgrip strength & $-0.33^{* *}$ & $0.39^{* *}$ & $-0.18^{* *}$ & - & $0.40^{* *}$ & $0.32^{* *}$ & $0.066^{* *}$ \\
\hline SPPB & $-0.42^{* *}$ & $0.43^{* *}$ & $-0.24^{* *}$ & $0.40^{* *}$ & - & $0.55^{* *}$ & $0.082^{* *}$ \\
\hline PCS & $-0.26^{* *}$ & $0.26^{* *}$ & $-0.25^{* *}$ & $0.32^{* *}$ & $0.55^{* *}$ & - & $-0.048^{* *}$ \\
\hline MCS & $0.063^{* *}$ & $0.049^{* *}$ & $-0.67^{* *}$ & $0.066^{* *}$ & $0.082^{* *}$ & $-0.048^{* *}$ & - \\
\hline
\end{tabular}

Note: ${ }^{*} p$-value $<0.05,{ }^{* *} p$-value $<0.001$ 


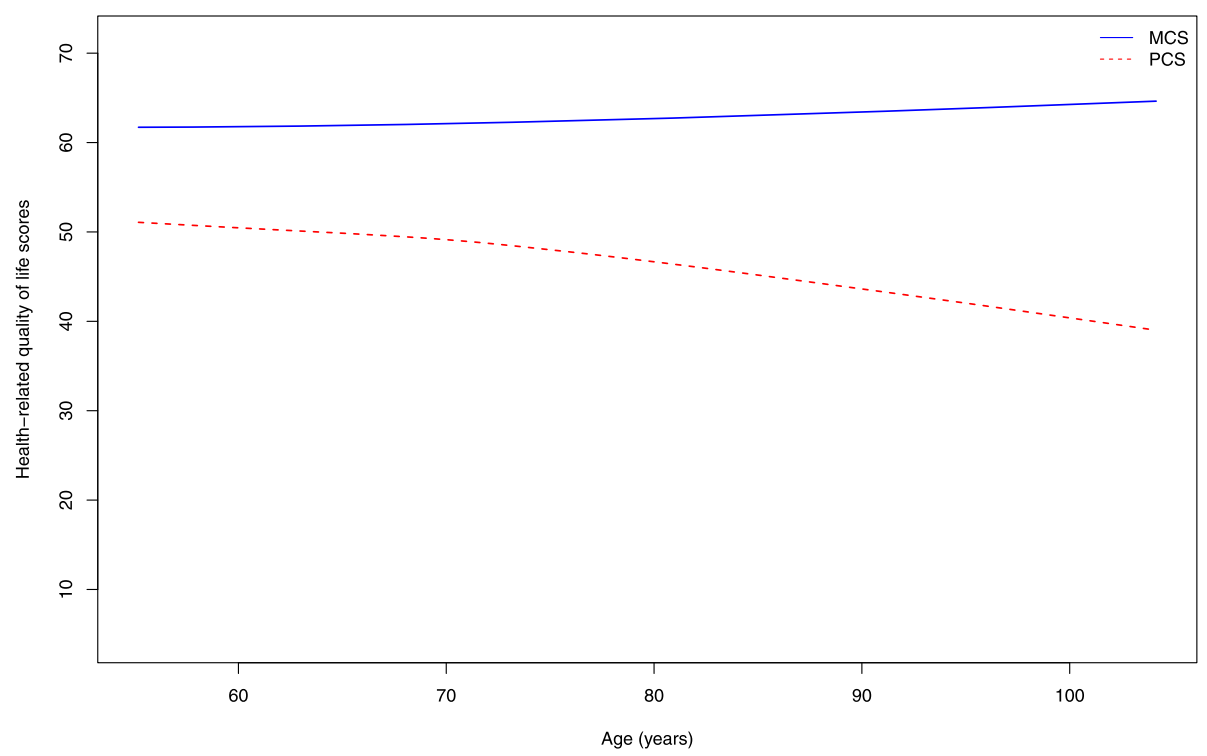

Fig. 2 LOESS fitted MCS and PCS curves over age

objective health indicators, the coefficients of associations with objective health indicators for MCS were relatively small compared to that for PCS.

Multiple regression analysis was used to further examine the age patterns of PCS and MCS and their associations with the different sets of predictors. Table 3 shows the results for PCS. Age was negatively associated with PCS (unstandardized coefficient $(B)=-0.28, \quad$ SE_B $=$ $0.015, p<.001)$, even after accounting for sociodemographic, mental, and cognitive covariates $\left(\mathrm{B}=-0.22, \mathrm{SE}_{-}\right.$ $\mathrm{B}=0.017, p<.001)$. In Model 3, which added objective health indicators, both handgrip strength and SPPB were

Table 3 Regressing PCS, showing unstandardized regression coefficients

\begin{tabular}{|c|c|c|c|c|}
\hline & \multicolumn{4}{|l|}{ PCS } \\
\hline & model 1 & model 2 & model 3 & model 4 \\
\hline Age & $-0.28(0.015)^{* *}$ & $-0.22(0.017)^{* *}$ & $-0.025(0.017)$ & $0.055(0.059)$ \\
\hline \multicolumn{5}{|l|}{ Covariates } \\
\hline Female (ref. male) & & $-1.73(0.26)^{* *}$ & $0.34(0.33)$ & $0.33(0.33)$ \\
\hline Elementary school (ref. illiterate) & & $-0.47(0.41)$ & $-0.45(0.36)$ & $-0.48(0.36)$ \\
\hline Middle school or higher (ref. illiterate) & & $0.30(0.47)$ & $0.27(0.42)$ & $0.20(0.42)$ \\
\hline Employed (ref. unemployed) & & $1.45(0.29)^{* *}$ & $0.86(0.26)^{* *}$ & $0.87(0.26)^{* *}$ \\
\hline Partnered (ref. unpartnered) & & $-0.39(0.31)$ & $-0.64(0.27)^{*}$ & $-0.67(0.28)^{*}$ \\
\hline Living in urban areas (ref. rural) & & $1.38(0.24)^{* *}$ & $1.15(0.21)^{* *}$ & $1.12(0.21)^{* *}$ \\
\hline Cohabitant (ref. alone) & & $-1.34(0.44)^{*}$ & $-0.92(0.39)^{*}$ & $-0.91(0.39)^{*}$ \\
\hline MMSE & & $0.22(0.043)^{* *}$ & $-0.080(0.039)^{*}$ & $-0.088(0.039)^{*}$ \\
\hline CES-D & & $-0.31(0.019)^{* *}$ & $-0.18(0.018)^{* *}$ & $-0.17(0.018)^{* *}$ \\
\hline \multicolumn{5}{|l|}{ Objective health indicators } \\
\hline Handgrip strength & & & $0.11(0.018)^{* *}$ & $-0.18(0.098)$ \\
\hline SPPB & & & $1.63(0.050)^{* *}$ & $3.07(0.42)^{* *}$ \\
\hline \multicolumn{5}{|l|}{ Interaction terms } \\
\hline Age*handgrip & & & & $0.0043(0.0014)^{*}$ \\
\hline Age $^{*}$ SPPB & & & & $-0.020(0.0056)^{* *}$ \\
\hline
\end{tabular}


positively associated with PCS $(\mathrm{B}=0.11 \& 1.63$, SE_B $=$ $0.018 \& 0.050$, ps $<.001)$, whereas age effects were reduced to non-significance, suggesting a mediation relationship. Adding physical function accounted for an additional $17 \%$ of the variance in PCS. The final model, including the significant interaction between age and physical health status, suggested that the strength of the predictive association of objective health on PCS became weaker with advancing age.

Table 4 shows the results for MCS. Age was positively associated with MCS $\left(\mathrm{B}=0.062, \mathrm{SE} \_\mathrm{B}=0.014, p<.001\right)$. This linear age effect became slightly stronger after accounting for covariates $\left(\mathrm{B}=0.075, \quad \mathrm{SE} \_\mathrm{B}=0.012\right.$, $p<.001)$. In Model 3, the linear effect of age remained significant once physical function was accounted for $\left(\mathrm{B}=0.063, \quad \mathrm{SE} \_\mathrm{B}=0.014, \quad p<.001\right)$. These results suggested that the impact of physical function on MCS did not differ among younger or older age groups. As seen in Model 3, a higher MCS score was also found among those with older age ( $\mathrm{B}=0.063$, SE_B $=0.014, p<.001$ ), illiteracy (as compared to middle or higher degree levels $(B=-1.02$, SE_B $=0.35, p<.05)$, fewer depressive symptoms $(\mathrm{B}=$ $\left.-0.93, S E \_B=0.015, p<.001\right)$, and worse lower limb function $\left(\mathrm{B}=-0.15, \mathrm{SE} \_\mathrm{B}=0.041, p<.001\right)$.

\section{Results not shown in the text}

Preliminary analyses did not find any evidence for quadratic or cubic age terms (ps $>.05$ ). Also, there was no significant gender difference found in the regression analysis. Therefore, subsequent analyses included only a linear age term and did not present a gender-split view of results. In addition, we excluded those with missing data in the main variables $(n=644,11.3 \%)$. To get a closer look at the potential effect of missing not at random on the present analyses, compared to the included/final sample, those excluded from the analyses were younger, less likely to be female, more likely to be employed, residing in urban areas, and have higher MMSE scores. There were no significant differences in the distributions of the primary outcome variables (PCS and MCS) and any objective health indicators between the included and excluded samples.

\section{Discussion}

The present study studied the aging paradox in quality of life by examining cross-sectional age patterns in HRQoL, as well as the role age plays in the associations between physical health and HRQoL (PCS and MCS, respectively).

Table 4 Regressing MCS, showing unstandardized regression coefficients

\begin{tabular}{|c|c|c|c|c|}
\hline & \multicolumn{4}{|l|}{ MCS } \\
\hline & model 1 & model 2 & model 3 & model 4 \\
\hline Age & $0.062(0.014)^{* *}$ & $0.075(0.012)^{* *}$ & $0.063(0.014)^{* *}$ & $0.050(0.049)$ \\
\hline \multicolumn{5}{|l|}{ Covariates } \\
\hline Female (ref. male) & & $0.14(0.19)$ & $0.13(0.27)$ & $0.13(0.27)$ \\
\hline Elementary school (ref. illiterate) & & $-0.55(0.30)$ & $-0.54(0.30)$ & $-0.54(0.30)$ \\
\hline Middle school or higher (ref. illiterate) & & $-1.03(0.35)^{*}$ & $-1.02(0.35)^{*}$ & $-1.01(0.35)^{*}$ \\
\hline Employed (ref. unemployed) & & $0.086(0.21)$ & $0.13(0.21)$ & $0.13(0.21)$ \\
\hline Partnered (ref. unpartnered) & & $-0.068(0.23)$ & $-0.042(0.23)$ & $-0.038(0.23)$ \\
\hline Living in urban areas (ref. rural) & & $0.26(0.18)$ & $0.28(0.18)$ & $0.29(0.18)$ \\
\hline Cohabitant (ref. alone) & & $-0.24(0.32)$ & $-0.27(0.32)$ & $-0.27(0.32)$ \\
\hline MMSE & & $-0.034(0.032)$ & $-0.011(0.032)$ & $-0.0094(0.032)$ \\
\hline CES-D & & $-0.92(0.014)^{* *}$ & $-0.93(0.015)^{* *}$ & $-0.93(0.015)^{* *}$ \\
\hline \multicolumn{5}{|l|}{ Objective health indicators } \\
\hline Handgrip strength & & & $0.0021(0.014)$ & $0.044(0.081)$ \\
\hline SPPB & & & $-0.15(0.041)^{* *}$ & $-0.36(0.35)$ \\
\hline \multicolumn{5}{|l|}{ Interaction terms } \\
\hline Age*handgrip & & & & $-0.00062(0.0012)$ \\
\hline Age $^{*}$ SPPB & & & & $0.0029(0.0046)$ \\
\hline
\end{tabular}

Note: $N=5022 .{ }^{*} p$-value $<0.05,{ }^{* *} p$-value< 0.001 . Model 1: age (unadjusted); model 2: same as model 1 plus demographic, SES, MMSE, and CES-D variables; model 3: same as model 2 plus objective health indicators; model 4: same as model 3 plus interactions between age and objective health indicators. Preliminary analyses did not find any evidence for quadratic or cubic age terms ( $p s>.05$ ); therefore, subsequent analyses included only a linear age term 


\section{Divergent age patterns of HRQoL in old age}

The present study described the cross-sectional age patterns of HRQoL. Consistent with our hypothesis, zeroorder correlations showed divergent age trajectories for PCS and MCS components of HRQoL. For our sample, older age was accompanied by more constraints in the physical domains (PCS), whereas HRQoL in the psychosocial domain (MCS) was preserved, if not slightly improved, with age.

When the age-related HRQoL covariates were controlled, not surprisingly we found no association between lower PCS and advancing age. The results, particularly with PCS, were in agreement with prior concerns that the paradox of well-being revealed by adjusted data for sociodemographic and health status could lead to a false and over-optimistic view regarding preserved quality of life in late life [22].

The positive association between advanced age and MCS, on the other hand, was in line with theoretical perspectives emphasizing motivational and self-regulatory mechanisms that allow older adults to maintain psychosocial well-being in the face of health-related losses.

As our results revealed a small and negative correlation between PCS and MCS, it seems reasonable to assume that cross-sectional age patterns may vary by domains of subjective well-being [19, 31]. Our results also confirmed Kunzmann et al.'s [27] suggestion that more pronounced age difference in subjective well-being may be detected in domain- and time-specific assessments as opposed to context- and time-neutral questions.

Perhaps one of the most surprising results was that even with raw data (i.e., not adjusted for other background and health variables), we saw a small but significant upturn of MCS in our sample. In previous studies $[9,35,44]$, the upturn of well-being and life satisfaction with age could be seen only after controlling for a series of SES- and health-related covariates. The relationship shown with the raw data deserves attention because it represents the actual age effect on HRQoL, considering all possible variations in every aspect of life as one ages.

Echoing prior research, it may not be realistic to expect a disease-free older age, considering the consistent cross-sectional associations found between age and constraints in physical function $[25,38]$. Instead, the robust findings of relatively preserved psychosocial aspects of HRQoL reiterate the need for future research to examine the specific mechanisms that protect older adults from the negative impact of objective health decrements.

The well-being paradox: associations among age, physical health, and HRQoL

The second objective of this study was to examine the association between objective health and subjective health-related QoL, and observe variations in the associations according to age. Consistent with our hypothesis, after controlling for covariates, the association between age and PCS was mediated by objective health status. The mediation pathways for age, objective health, and PCS suggested that physical health status, rather than age, is the best predictor for the inter- and intrapersonal differences in PCS. Interestingly, however, the predictive value of objective health status for subjective QoL became weaker with advancing age in this Taiwanese older adults sample. This seemingly counterintuitive result corresponds to the paradox of aging phenomenon found in Western and highly industrialized countries.

In contrast to the analyses for PCS, the associations between MCS and objective health did not vary by age, and controlling for objective health did not further strengthen the slightly positive association between MCS and age. As noted in the introduction, variables beyond chronological age - including self-regulation, perceived control, social comparison, and social integration - may potentially affect the association between objective health and MCS, and should be explored in future research.

\section{Limitations}

Our results need to be interpreted within the context of the study limitations. First, the cross-sectional nature of the study did not allow us to investigate longitudinal shifts in the associations among age and subjective HRQoL. Second, we were unable to determine if the observed age pattern was a result of cohort effects or a genuine representation of the aging effect. A longitudinal study would provide more insights into the relative role of age and into age-related differences in the effects of functional health on HRQoL, as well as cohort effects in HRQoL. Third, self-reported HRQoL may be subject to various kinds of bias, such as social desirability, that we were unable to evaluate with our dataset. We also acknowledged that self-reported health care and other disease-related data are important variables for HRQoL; however, they were not quite consistent with the insurance records. Thus, we included objective health-related variables as covariates. Fourth, it is worth noting that by focusing on community-dwelling adults a relatively healthier portion of the aging population in Taiwan have been selected. The results may not be generalizable to frailer older adults who are more likely to be institutionalized. Finally, the study was part of a larger cohort study [23], and the research question can be analyzed only within the boundaries of the original study.

\section{Conclusions}

Notwithstanding these limitations, to the best of our knowledge, this is the first study with a representative 
cohort sample that used a well-validated measure of HRQoL to assess age differences in subjective well-being and to examine age-related shifts in the association between objective health and HRQoL, thus obtaining evidence for the paradox of aging in East Asia. Although our results may not be directly comparable to those of other well-established studies in the West (e.g., the ELSA, the Berlin Aging Study, the Veterans Affairs Normative Aging Study, the World Gallup Poll, the US General Social Survey, the British Household panel, Eurobarometer, and the National Health and Nutrition Examination Surveys), considering the differences in sample characteristics (age groups and health status), and measures (assessing happiness, positive or negative effect, and life satisfaction), our results showed similar conclusions that are complementary to these studies: The third age can be a period with high subjective quality of life.

Furthermore, these results are consistent with the aforementioned theoretical frameworks, suggesting mechanisms that allow for the preservation of HRQoL, especially MCS, in spite of objective health detriments among older adults. Future studies should systematically evaluate specific psychosocial variables implicated by these theories (e.g., time perspective, perceived control, social comparison, and interpersonal embeddedness) [1, $6,8,9,39,47]$ to examine their relative contributions to the observed age patterns. In the long run, a better understanding of these variables could be leveraged to promote continued HRQoL even among those individuals who face considerable functional health threats in their later years.

\section{Abbreviations \\ ADL: Activities of daily living; CES-D: Center for Epidemiologic Studies Depression Scale; ELSA: English Longitudinal Study of Aging; HALST: Healthy Aging Longitudinal Study in Taiwan; HRQoL: Health-related quality of life; LOESS: Locally regression smoothing method; MCS: Mental component summary score; MMSE: The Mini-Mental State Examination; PCS: Physical component summary score; SES: Socioeconomic status; SF-12v2: 12-item Short Form Health Survey (version 2); SF-36: 36-item Short Form Health Survey; SPPB: Short Physical Performance Battery}

\section{Acknowledgments}

We thank all the HALST participants and the members of the HALST study group; in particular, to Mr. Rui-Ching Wu, for his dedicated efforts on data management.

\section{Authors' contributions \\ HYT: data acquisition and interpretation, and manuscript writing; Corinna Löckenhoff: data interpretation and manuscript writing; CYL: data analysis; SHY, ICW, and HYC: data acquisition and study concept and design; YFC: study design, data analysis and interpretation, and manuscript writing; $\mathrm{CH}$ : obtaining funding, data acquisition and study design. All authors read and approved the final manuscript.}

\section{Funding}

This work was supported by the National Health Research Institutes (project no. PH-97 109-SP-01, PH-101 109-PP-04). NHRI had no role in the study design, data collection, analysis, interpretation, and writing the manuscript.

\section{Availability of data and materials}

The datasets generated and/or analyzed during the current study are not publicly available due to participant confidentiality.

\section{Ethics approval and consent to participate}

Written informed consent was obtained from each participant, this study was approved by the Research Ethics Committee at National Health Research Institutes (NHRI) (reference number EC1020805-R1).

\section{Consent for publication}

Not applicable.

\section{Competing interests}

The authors declare that they have no competing interests.

\section{Author details}

${ }^{1}$ Institute of Population Health Sciences, National Health Research Institutes, 35 Keyan Rd., Zhunan, Miaoli County 35053, Taiwan. ${ }^{2}$ Department of Human Development, Cornell University, G60B Martha Van Rensselaer Hall, 116 Reservoir Ave, Ithaca, NY 14853, USA. ${ }^{3}$ Aesthetic-Mind Clinic, 334 Dasheng St, Nantun District 408, Taichung City, Taiwan

Received: 23 September 2019 Accepted: 27 January 2020

Published online: 05 March 2020

\section{References}

1. Antonucci TC, Ajrouch KJ, Birditt KS. The convoy model: explaining social relations from a multidisciplinary perspective. The Gerontologist. 2014;54(1): 82-92. https://doi.org/10.1093/geront/gnt118.

2. Barrera M. Distinctions between social support concepts, measures, and models. Am J Community Psychol. 1986;14(4):413-45. https://doi.org/10. 1007/BF00922627.

3. Bengtson $\mathrm{VL}$, Elder GH, Putney NM. The lifecourse perspective on ageing: linked lives, timing, and history. In: Johnson ML, editor. The Cambridge Handbook of Age and Ageing. Cambridge: Cambridge University Press; 2005. p. 493-501. https://doi.org/10.1017/CBO9780511610714.053.

4. Blanchflower DG, Oswald AJ. Is well-being U-shaped over the life cycle? Soc Sci Med. 2008;66(8):1733-49. https://doi.org/10.1016/.j.socscimed.2008.01.030.

5. Bowling A. Ageing well: quality of life in old age. Maidenhead, England: Open University Press; 2005. https://www.questia.com/library/119516697/ ageing-well-quality-of-life-in-old-age.

6. Carstensen LL, Pasupathi M, Mayr U, Nesselroade JR. Emotional experience in everyday life across the adult life span. J Pers Soc Psychol. 2000;79(4): 644-55. https://doi.org/10.1037//0022-3514.79.4.644.

7. Case A, Deaton A. Rising morbidity and mortality in midlife among white non-Hispanic Americans in the 21st century. Proc Nat Acad Sci. 2015;112: 15078-83. https://doi.org/10.5324/nje.v22i2.1565.

8. Charles ST, Mather M, Carstensen LL. Aging and emotional memory: the forgettable nature of negative images for older adults. J Exp Psychol Gen. 2003;132(2):310-24. https://doi.org/10.1037/0096-3445.132.2.310.

9. Chen C. Aging and life satisfaction. Soc Indic Res. 2001;54(1):57-79. https:// doi.org/10.1023/A:1007260728792.

10. Clark AE, Oswald AJ. Unhappiness and unemployment. Econ J. 1994; 104(424):648-59. https://doi.org/10.2307/2234639.

11. Clark, A. E., \& Oswald, A. J. (2006). The curved relationship between subjective well-being and age. HAL Archives. https://halshs.archivesouvertes.fr/halshs-00590404. Accessed 11 Jul 2019.

12. Cullen B, O'Neill B, Evans JJ, Coen RF, Lawlor BA. A review of screening tests for cognitive impairment. J Neurol Neurosurg Psychiatry. 2007;8(790-799). https://doi.org/10.1136/jnnp.2006.095414.

13. Diener E, Suh ME, Lucas RE, Smith HL. Subjective well-being: three decades of progress. Psychol Bull. 1999;125(2):276-302. https://doi.org/10.1093/ geront/gnt118.

14. Dumitrache CG, Rubio L, Rubio-Herrera R. Perceived health status and life satisfaction in old age, and the moderating role of social support. Aging Ment Health. 2017;21(7):751-7. https://doi.org/10.1080/13607863.2016. 1156048.

15. Farivar SS, Cunningham WE, Hays RD. Correlated physical and mental health summary scores for the SF-36 and SF-12 health survey, V.I. Health Qual Life Outcomes. 2007;5:54. https://doi.org/10.1186/1477-7525-5-54. 
16. Folstein MF, Folstein SE, McHugh PR. "Mini-mental state". A practical method for grading the cognitive state of patients for the clinician. J Psychiatr Res. 1975;12(3):189-98. https://doi.org/10.1002/(SICI)10991166(199805)13:5\%3C285::AID-GPS753\%3E3.3.CO;2-M.

17. Frijters $P$, Beatton $T$. The mystery of the $U$-shaped relationship between happiness and age. J Econ Behav Organ. 2012;82(2):525-42. https://doi.org/ 10.1016/j.jebo.2012.03.008.

18. Groessl EJ, Kaplan RM, Rejeski WJ, Katula JA, King AC, Frierson G, et al. Health-related quality of life in older adults at risk for disability. Am J Prev Med. 2007;33(3):214-8. https://doi.org/10.1016/j.amepre.2007.04.031.

19. The WHOQOL Group. The World Health Organization quality of life assessment (WHOQOL): position paper from the World Health organization. Soc Sci Med. 1995;41(10):1403-9. https://doi.org/10.1016/02779536(95)00112-K.

20. Guralnik JM, Ferrucci L, Pieper CF, Leveille SG, Markides KS, Ostir GV, et al. Lower extremity function and subsequent disability: consistency across studies, predictive models, and value of gait sppd alone compared with the short Physicla performance battery. The Journals of Gerontology, Series A. 2000;55(4):221-31. https://doi.org/10.1093/gerona/55.4.M221.

21. Guralnik JM, Simonsick EM, Ferrucci L, Glynn RJ, Berkman LF, Blazer DG, et al. A short physical performance battery assessing lower extremity function: association with self-reported disability and prediction of mortality and nursing home admission. J Gerontol. 1994;49(2):85-94. https://doi.org/ 10.1093/geronj/49.2.M85.

22. Hansen T, Slagsvold B. The age and subjective well-being paradox revisited: a multidimensional perspective. Norsk Epidemiologi. 2012;22(2). https://doi. org/10.5324/nje.v22i2.1565.

23. Hsu CC, Chang HY, Wu IC, Chen CC, Tsai HJ, Chiu YF, et al. Cohort profile: the healthy aging longitudinal study in Taiwan (HALST). Int J Epidemiol. 2017;46(4):1106. https://doi.org/10.1093/ije/dyw331.

24. Idler EL. Age differences in self-assessments of health: age changes, cohort differences, or survivorship? J Gerontol. 1993;48(6):289-300. https://doi.org/ 10.1093/geronj/48.6.S289.

25. Katz S, Calasanti T. Critical perspectives on successful aging: does it "appeal more than it illuminates"? The Gerontologist. 2015;55(1):26-33. https://doi. org/10.1093/geront/gnu027.

26. Kim HS, Bae NK, Kwon IS, Cho YC. Relationship between status of physical and mental function and quality of life among the elderly people admitted from long-term care insurance. J Prev Med Public Health. 2010;43(4):319-29. https://doi.org/10.3961/jpmph.2010.43.4.319.

27. Kunzmann U, Little TD, Smith J. Is age-related stability of subjective wellbeing a paradox? Cross-sectional and longitudinal evidence from the Berlin aging study. Psychol Aging. 2000;15(3):511-26. https://doi.org/10.1037/08827974.15.3.511.

28. Lam CLK, Tse EYY, Gandek B. Is the standard SF-12 health survey valid and equivalent for a Chinese population? Qual Life Res. 2005;14(2):539-47. https://doi.org/10.1007/s11136-004-0704-3.

29. Li Cl, Lin CH, Lin WY, Liu CS, Chang CK, Meng NH, et al. Successful aging defined by health-related quality of life and its determinants in communitydwelling elders. BMC Public Health. 2014;14(1):10-1186. https://doi.org/10. 1186/1471-2458-14-1013.

30. Lin JP. Life satisfaction among older adults in Taiwan: the effects of marital relations and intergenerational relations. In: Successful Aging. Dordrecht: Springer; 2015. p. 179-98. https://doi.org/10.1007/978-94-017-9331-5_11.

31. McAdams KK, Lucas RE, Donnellan MB. The role of domain satisfaction in explaining the paradoxical association between life satisfaction and age. Soc Indic Res. 2012;109(2):295-303. https://doi.org/10.1007/s11205-011-9903-9.

32. Melville MR, Lari MA, Brown N, Young T, Gray D. Quality of life assessment using the short form 12 questionnaire is as reliable and sensitive as the short form 36 in distinguishing symptom severity in myocardial infarction survivors. Heart. 2003;89(12):1445-6. https://doi.org/10.1136/heart.89.12.1445.

33. Mroczek DK, Kolarz CM. The effect of age on positive and negative affect: a developmental perspective on happiness. J Pers Soc Psychol. 1998;75(5): 1333-49. https://doi.org/10.1037//0022-3514.75.5.1333.

34. Mroczek DK, Spiro A. Change in life satisfaction during adulthood: findings from the veterans affairs normative aging study. J Pers Soc Psychol. 2005; 88(1):189-202. https://doi.org/10.1037/0022-3514.88.1.189.

35. Netuveli G, Wiggins RD, Hildon Z, Montgomery SM, Blane D. Quality of life at older ages: evidence from the English longitudinal study of aging (wave 1). J Epidemiol Community Health. 2006;60(4):357-63. https://doi.org/10. 1136/jech.2005.040071.
36. Oishi S, Diener E, Suh E, Lucas RE. Value as a moderator in subjective wellbeing. J Pers. 1999;67:157-84. https://doi.org/10.1111/1467-6494.00051.

37. Radloff LS. The CES-D scale: a self-report depression scale for research in the general population. Appl Psychol Meas. 1977;1(3). https://doi.org/10.1177/ 014662167700100306.

38. Rubinstein RL, de Medeiros K. "Successful aging," gerontological theory and neoliberalism: a qualitative critique. The Gerontologist. 2015;55(1):34-42. https://doi.org/10.1093/geront/gnu080.

39. Schulz R, Heckhausen J. A life span model of successful aging. Am Psychol. 1996;51(7):702-14. https://doi.org/10.1037/0003-066X.51.7.702.

40. Shields, M., \& Wooden, M. (2003). Marriage, children and subjective wellbeing. In 8th Australian Institute of Family Studies Conference. Open access academic: Semantic Scholar. https://pdfs.semanticscholar.org/fe2a/5a73d44 748192d88cc931581e162e1b4bb92.pdf. Accessed 11 Jul 2019.

41. Siedlecki KL, Tucker-Drob EM, Oishi S, Salthouse TA. Life satisfaction across adulthood: different determinants at different ages? J Posit Psychol. 2008; 3(3):153-64. https://doi.org/10.1080/17439760701834602.

42. Spini D, Jopp D, Pin S, Stringhini S. The multiplicity of aging: lessons for theory and conceptual development from longitudinal studies. In: Handbook of Theories of Aging; 2016. p. 669-90. https://doi.org/10.1891/ 9780826129437.0002.

43. Steptoe A, Deaton A, Stone AA. Subjective wellbeing, health, and ageing. Lancet. 2015;385(9968):640-8. https://doi.org/10.1016/S0140-6736(13)61489-0.

44. Sun S, Chen J, Johannesson M, Kind P, Burström K. Subjective well-being and its association with subjective health status, age, sex, region, and socioeconomic characteristics in a Chinese population study. J Happiness Stud. 2016;17(2):833-73. https://doi.org/10.1007/s10902-014-9611-7.

45. Ware J, Kosinski M, Keller SD. A 12-item short-form health survey: construction of scales and preliminary tests of reliability and validity. Med Care. 1996;34(3):220-33. https://doi.org/10.1097/00005650-199603000-00003.

46. Ware J, Kosinski M, Turner-Bowker D, Gandek B. How to score version 2 of the SF-12 HEALTH survey. Lincoln, RI: Quality Metric Incorporated; 2002. https://doi.org/10.1186/s12913-018-3743-0.

47. Wilson AE, Ross M. The frequency of temporal-self and social comparisons in people's personal appraisals. J Pers Soc Psychol. 2000;78(5):928-42. https://doi.org/10.1037//0022-3514.78.5.928.

\section{Publisher's Note}

Springer Nature remains neutral with regard to jurisdictional claims in published maps and institutional affiliations.

Ready to submit your research? Choose BMC and benefit from:

- fast, convenient online submission

- thorough peer review by experienced researchers in your field

- rapid publication on acceptance

- support for research data, including large and complex data types

- gold Open Access which fosters wider collaboration and increased citations

- maximum visibility for your research: over $100 \mathrm{M}$ website views per year

At BMC, research is always in progress.

Learn more biomedcentral.com/submissions 